\title{
Diversity of Borrelia burgdorferi Sensu Lato Evidenced by Restriction Fragment Length Polymorphism of $r r f$ (5S)-rrl (23S) Intergenic Spacer Amplicons
}

\author{
DANIELE POSTIC, ${ }^{1 *}$ MARC V. ASSOUS, ${ }^{1} \dagger$ PATRICK A. D. GRIMONT, ${ }^{2}$ AND GUY BARANTON ${ }^{1}$ \\ Unité de Bactériologie Moléculaire et Médicale, ${ }^{1}$ and Unité des Entérobactéries, Institut National de la Santé et de la \\ Recherche Médicale, Unité 389, ${ }^{2}$ Institut Pasteur, 75724 Paris Cedex 15, France
}

\begin{abstract}
The organization of the ribosomal genes is unique in Borrelia burgdorferi in that the $r r l$ (23S) and $r r f(5 S)$ genes are tandemly duplicated. We took advantage of this uniqueness to assess the restriction polymorphism of PCR products obtained with primers at the $3^{\prime}$ end of the first $r r f$ gene and at the 5 ' end of the second $r r l$ gene. An amplicon that was 226 to 266 bp long was generated from 99 of 100 B. burgdorferi sensu lato strains. The nuclease $M s e I$ restriction polymorphism of the amplicons provided a useful tool for identifying $B$. burgdorferi sensu stricto, Borrelia garinii, Borrelia afzelii (formerly group VS461), and Borrelia japonica (formerly group F63B). Furthermore, it allowed us to recognize four new genomic groups, which were confirmed by DNA-DNA hybridization data. Two of these genomic groups comprised European strains, and the other two groups contained American strains. The American genomic groups involved vectors with enzootic cycles quite different from those of $B$. burgdorferi sensu stricto, which previously was the only Lyme disease Borrelia species known to occur in the United States. Our method could be used for rapid screening of strain collections and for epidemiological and medical purposes.
\end{abstract}

Since the first description of Borrelia burgdorferi in 1984 (20), numerous strains have been isolated throughout the world. Using the reference method for delineation of bacterial species, DNA-DNA hybridization, workers have described three species associated with Lyme borreliosis, B. burgdorferi sensu stricto, Borrelia garinii, and Borrelia afzelii (formerly group VS461). In addition, a new nonpathogenic species seems to be restricted to Japan; this species was described as group F63B (30) and has been named Borrelia japonica (21). Recently, two new American genomic groups were identified on the basis of the results of a fla gene-based PCR assay (6). One interesting aspect of the species classification described above is its correlation with epidemiological and clinical features $(5,41)$. $B$. burgdorferi sensu stricto is present both in the Old World and in the New World, but it seems to be absent from Asia. Moreover, $B$. burgdorferi, the only Lyme disease Borrelia species known to occur in the United States, is mainly associated with arthritic forms of Lyme disease. $B$. garinii and $B$. afzelii are present in Europe and Asia; the former is frequently associated with neurological manifestations, and the latter seems to be the exclusive agent of late cutaneous lesions of acrodermatitis chronica atrophicans (Pick-Herxheimer disease), which occurs mainly in northern Europe $(13,41,44)$.

Genetic diversity among Borrelia isolates, both at the interspecific level and at the infraspecific level, has been investigated by different approaches, including sodium dodecyl sulfate-polyacrylamide gel electrophoresis $(1,28)$, multilocus enzyme electrophoresis (11), DNA restriction enzyme analysis (23), ribotyping (7), plasmid profile analysis $(8,16,39)$, and pulsed-field gel electrophoresis (9). The disadvantage of all of these methods is that they require large quantities of the bacteria, which are fastidious and difficult to grow. In contrast,

\footnotetext{
* Corresponding author. Mailing address: Unité de Bactériologie Moléculaire et Médicale, Institut Pasteur, 28 rue du Docteur Roux, 75724 Paris Cedex 15, France. Phone: 331456883 37. Fax: 3314061 30 01. Electronic mail address: dpostic@pasteur.fr.

† Present address: Faculté de Médecine Cochin-Port-Royal, 75674 Paris Cedex 14, France.
}

PCR methods do not require DNA extraction or a large culture volume. Different templates have been used for these PCR $(2,25,27,29,33,37)$.

In this study our objective was to develop a simple epidemiological and diagnostic tool to assess rapidly the genetic diversity of $B$. burgdorferi sensu lato strains. Because of the organization of the rRNA genes in the genus Borrelia $(18,38)$ and the uniqueness of the tandemly repeated $23 \mathrm{~S}(\mathrm{rrl})-5 \mathrm{~S}(\mathrm{rrf})$ rRNA genes among bacteria, we used the intergenic spacer $r f f-r r l$ as a template for amplification and for a restriction polymorphism analysis of the amplified sequence.

\section{MATERIALS AND METHODS}

Bacterial strains. Table 1 lists the 100 Borrelia strains (which were mostly high-passage strains) that were used in this study and their origins. A total of 30 of these strains were $B$. burgdorferi sensu stricto, 28 were $B$. garinii, 19 were $B$. afzelii, and 5 were $B$. japonica, as previously identified by DNA-DNA hybridization experiments, reactivity with monoclonal antibodies, and ribotyping $(7,13,30)$. Eighteen strains were unclassified. Ninety-nine strains were grown in BSKII medium at $34^{\circ} \mathrm{C}$. A small amount of strain NE57 DNA was kindly provided by J. Meyer. The pellet from $2 \mathrm{ml}$ of culture was washed and resuspended in $100 \mu \mathrm{l}$ of distilled water before the preparation was boiled at $100^{\circ} \mathrm{C}$ for $10 \mathrm{~min}$. This suspension was used for PCR. Strains of Borrelia hermsii, Borrelia parkeri, Borrelia turicatae, Leptospira interrogans, Serpulina hyodysenteriae, and Escherichia coli were used as controls.

PCR. A primer set (primer 1 [5'-CTGCGAGTTCGCGGG AGA-3'] and primer 2 [5'-TCCTAGGCATTCACCATA-3']) was chosen on the basis of a previously published ribosomal DNA sequence (38) and was used to amplify the variable spacer region between two conserved structures, the $3^{\prime}$ end of the 5S rRNA $(r f)$ and the $5^{\prime}$ end of the $23 \mathrm{~S}$ rRNA $(r r l)$. The uniqueness of the Borrelia rRNA gene organization among bacteria made these primers suitable for specific identification of Borrelia strains despite the lack of primer specificity. The PCR was performed in $50 \mu \mathrm{l}$ of a solution containing $10 \mathrm{mM}$ 
TABLE 1. Origins and rrl-rrf RFLP patterns of B. burgdorferi sensu lato strains used in this study

\begin{tabular}{|c|c|c|c|c|}
\hline \multirow{2}{*}{ Isolate } & \multirow{2}{*}{ Source } & \multirow{2}{*}{ Country } & \multicolumn{2}{|c|}{ RFLP patterns ${ }^{a}$} \\
\hline & & & DraI & Msel \\
\hline \multicolumn{5}{|c|}{ B. burgdorferi sensu stricto } \\
\hline IP1 & Human $(\mathrm{CSF})^{b}$ & France & ND & A \\
\hline IP2 & Human (CSF) & France & $\mathbf{A}^{\prime}$ & A \\
\hline IP3 & Human (CSF) & France & ND & A \\
\hline 297 & Human (CSF) & United States & A & A \\
\hline Z118 & Ixodes ricinus & Germany & ND & A \\
\hline Z136 & Lxodes ricinus & Germany & ND & A \\
\hline 212 & Lxodes ricinus & France & $\mathrm{A}^{\prime}$ & A \\
\hline B31 & Ixodes scapularis & United States & $\mathrm{A}^{\prime}$ & A \\
\hline Charlie tick & Lxodes scapularis & United States & ND & A \\
\hline 19535 & Peromyscus leucopus & United States & $\mathrm{A}^{\prime}$ & A \\
\hline 21305 & Peromyscus leucopus & United States & $\mathbf{A}^{\prime}$ & A \\
\hline 27985 & Ixodes scapularis & United States & $\mathrm{A}^{\prime}$ & A \\
\hline 26816 & Microtus pensylvanicus & United States & $\mathrm{A}^{\prime}$ & A \\
\hline HUM 3336 & Lxodes pacificus & United States & $\mathrm{A}^{\prime}$ & A \\
\hline SON 328 & Ixodes pacificus & United States & $\mathrm{A}^{\prime}$ & A \\
\hline HUM 7814 & Ixodes pacificus & United States & $\mathrm{A}^{\prime}$ & A \\
\hline MEN 115 & Ixodes pacificus & United States & $\mathrm{A}^{\prime}$ & A \\
\hline SON 188 & Lxodes pacificus & United States & $\mathrm{A}^{\prime}$ & A \\
\hline LAKE 339 & Ixodes pacificus & United States & $\mathrm{A}^{\prime}$ & $\mathrm{A}$ \\
\hline CA5 & Ixodes pacificus & United States & ND & A \\
\hline VS2 & Lxodes scapularis & United States & $\mathrm{A}^{\prime}$ & A \\
\hline NY1-86 & Human (skin) & United States & $\mathrm{A}^{\prime}$ & A \\
\hline Veery & Bird & United States & $\mathrm{A}^{\prime}$ & A \\
\hline SV1 & Ixodes ricinus & France & $\mathrm{A}^{\prime}$ & A \\
\hline SV3 & Lxodes ricinus & France & $\mathrm{A}^{\prime}$ & A \\
\hline ESP1 & Ixodes ricinus & Spain & $\mathrm{A}^{\prime}$ & A \\
\hline Cat Flea Texas & Cat flea & United States & $\mathbf{A}^{\prime}$ & A \\
\hline Texas skin & Human (skin) & United States & ND & A \\
\hline HII & Human (blood) & Italy & ND & A \\
\hline GeHo & Human (skin) & Germany & ND & A \\
\hline \multicolumn{5}{|l|}{ B. garinii } \\
\hline 20047 & Ixodes ricinus & France & $\mathrm{B}^{\prime}$ & $\mathrm{B}$ \\
\hline G25 & Ixodes ricinus & Sweden & ND & B \\
\hline N34 & Ixodes ricinus & Germany & $\mathrm{B}^{\prime}$ & $\mathrm{B}$ \\
\hline 153 & Ixodes ricinus & France & $\mathbf{B}^{\prime}$ & B \\
\hline VS185 & Ixodes ricinus & Switzerland & ND & B \\
\hline VS286 & Ixodes ricinus & Switzerland & ND & B \\
\hline VS468 & Ixodes ricinus & Switzerland & ND & $\mathrm{B}$ \\
\hline $\mathrm{PBi}$ & Human (CSF) & Germany & $\mathrm{B}^{\prime}$ & B \\
\hline $\mathrm{PBr}$ & Human (CSF) & Germany & ND & B \\
\hline $\mathrm{T} 25$ & Ixodes ricinus & Germany & $\mathbf{B}^{\prime}$ & $\mathrm{B}$ \\
\hline HP3 & Ixodes persulcatus & Japan & $\mathrm{B}^{\prime}$ & $\mathrm{B}$ \\
\hline $\mathrm{TN}$ & Ixodes ricinus & Germany & ND & $\mathrm{B}$ \\
\hline NBS16 & Ixodes ricinus & Sweden & $\mathrm{B}^{\prime}$ & B \\
\hline G152 & Ixodes ricinus & Sweden & $\mathrm{B}^{\prime}$ & B \\
\hline FujiP1 & Ixodes persulcatus & Japan & $\mathrm{B}^{\prime}$ & B \\
\hline FujiP2 & Ixodes persulcatus & Japan & $\mathrm{B}^{\prime}$ & B \\
\hline SV2 2 & Ixodes ricinus & France & $\mathrm{B}^{\prime}$ & B \\
\hline AR-1 & Ixodes ricinus & The Netherlands & $\mathrm{B}^{\prime}$ & B \\
\hline PD89 & Human (blood) & People's Republic of China & $\mathrm{B}^{\prime}$ & B \\
\hline Ir210 & Ixodes ricinus & Russia & $\mathrm{B}^{\prime}$ & $\mathrm{B}$ \\
\hline Sika1 & Ixodes ovatus & Japan & $\mathrm{B}^{\prime}$ & $\mathrm{B}$ \\
\hline Sika2 & Ixodes persulcatus & Japan & $\mathrm{B}^{\prime}$ & $\mathrm{B}$ \\
\hline P526d & Ixodes persulcatus & Japan & $\mathrm{B}^{\prime}$ & B \\
\hline HP13 & lxodes persulcatus & Japan & $\mathrm{B}^{\prime}$ & B \\
\hline K48 & Ixodes ricinus & Slovakia & ND & B \\
\hline BITS & Ixodes ricinus & Italy & ND & B \\
\hline NT29 & Ixodes persulcatus & Japan & $\mathrm{C}^{\prime}$ & $\mathrm{C}$ \\
\hline Ip89 & Ixodes persulcatus & Russia & $\mathrm{C}^{\prime}$ & $\mathrm{C}$ \\
\hline \multicolumn{5}{|l|}{ B. afzelii } \\
\hline VS461 & Ixodes ricinus & Switzerland & $\mathrm{D}^{\prime}$ & $\mathrm{D}$ \\
\hline IPer3 & Ixodes ricinus & Russia & $\mathrm{D}^{\prime}$ & $\mathrm{D}$ \\
\hline Ip21 & Ixodes persulcatus & Russia & $\mathrm{D}^{\prime}$ & $\mathrm{D}$ \\
\hline M7 & Ixodes persulcatus & People's Republic of China & $\mathrm{D}^{\prime}$ & $\mathrm{D}$ \\
\hline 2246 & Ixodes persulcatus & People's Republic of China & $\mathrm{D}^{\prime}$ & $\mathrm{D}$ \\
\hline
\end{tabular}


TABLE 1 - Continued

\begin{tabular}{|c|c|c|c|c|}
\hline \multirow{2}{*}{ Isolate } & \multirow{2}{*}{ Source } & \multirow{2}{*}{ Country } & \multicolumn{2}{|c|}{ RFLP patterns ${ }^{a}$} \\
\hline & & & Dral & MseI \\
\hline $\mathrm{IpF}^{c}$ & Ixodes persulcatus & Japan & $\mathrm{D}^{\prime}$ & $\mathrm{D}$ \\
\hline $\mathrm{P} 427 \mathrm{a}$ & Ixodes persulcatus & Japan & ND & $\mathrm{D}$ \\
\hline PSto & Human (skin) & Germany & ND & $\mathrm{D}$ \\
\hline $\mathrm{BO} 23$ & Human (skin) & Germany & $\mathrm{D}^{\prime}$ & $\mathrm{D}$ \\
\hline UM01 & Human (skin) & Sweden & $\mathrm{D}^{\prime}$ & $\mathrm{D}$ \\
\hline PGau & Human (skin) & Germany & ND & $\mathrm{D}$ \\
\hline PKo-85 & Human (skin) & Germany & $\mathrm{D}^{\prime}$ & $\mathrm{D}$ \\
\hline DK3 & Human (skin) & Denmark & ND & $\mathrm{D}$ \\
\hline DK8 & Human (skin) & Denmark & $\mathrm{D}^{\prime}$ & D \\
\hline ACA1 & Human (skin) & Sweden & ND & $\mathrm{D}$ \\
\hline ECM1 & Human (skin) & Sweden & $\mathrm{D}^{\prime}$ & $\mathrm{D}$ \\
\hline SmS1 & Apodemus flavicollis & Sweden & $\mathrm{D}^{\prime}$ & $\mathrm{D}$ \\
\hline LABC & Human (skin) & Sweden & ND & D \\
\hline Nancy & Human & Italy & ND & $\mathrm{D}$ \\
\hline \multicolumn{5}{|l|}{ B. japonica } \\
\hline Ika2 & Ixodes ovatus & Japan & & \\
\hline HO14 & Ixodes ovatus & Japan & NS & $\mathrm{E}$ \\
\hline Cow611C & Ixodes ovatus & Japan & NS & $\mathrm{E}$ \\
\hline O612 & Ixodes ovatus & Japan & NS & $\mathrm{E}$ \\
\hline F63B & Ixodes ovatus & Japan & NS & $\mathrm{E}$ \\
\hline \multicolumn{5}{|l|}{ Group VS116 } \\
\hline VS116 & Ixodes ricinus & Switzerland & $\mathbf{B}^{\prime \prime}$ & $\mathrm{F}$ \\
\hline UK & Ixodes ricinus & England & $\mathbf{B}^{\prime \prime}$ & $\mathrm{F}$ \\
\hline $\mathrm{NE} 57^{d}$ & Ixodes ricinus & Switzerland & ND & $\mathrm{F}$ \\
\hline \multicolumn{5}{|l|}{ Group PotiB2 } \\
\hline PotiB1 & Ixodes ricinus & Portugal & $G^{\prime}$ & $\mathrm{G}$ \\
\hline PotiB2 & Ixodes ricinus & Portugal & $\mathrm{G}^{\prime}$ & $\mathrm{G}$ \\
\hline PotiB3 & Lxodes ricinus & Portugal & $\mathrm{H}^{\prime}$ & $\mathbf{H}$ \\
\hline \multicolumn{5}{|l|}{ Group DN127 } \\
\hline DN127 & Ixodes pacificus & United States & $\mathrm{I}^{\prime}$ & I \\
\hline CA118 & Ixodes neotomae & United States & $\mathrm{J}^{\prime}$ & $\mathbf{J}$ \\
\hline CA128 & Ixodes neotomae & United States & $\mathrm{J}^{\prime}$ & $\mathbf{J}$ \\
\hline CA55 & Ixodes neotomae & United States & $\mathrm{J}^{\prime}$ & $\mathbf{J}$ \\
\hline CA127 & Ixodes neotomae & United States & $\mathbf{J}^{\prime}$ & $\mathrm{J}$ \\
\hline 25015 & Ixodes scapularis & United States & $\mathrm{K}^{\prime}$ & $\mathrm{K}$ \\
\hline \multicolumn{5}{|l|}{ Group 21123} \\
\hline 21123 & Ixodes dentatus & United States & NS & $\mathrm{L}$ \\
\hline 21133 & Ixodes dentatus & United States & NS & $\mathrm{L}$ \\
\hline 19952 & Ixodes dentatus & United States & ND & $\mathrm{L}$ \\
\hline 19865 & Rabbit (kidney) & United States & NS & $\mathrm{L}$ \\
\hline 19857 & Rabbit (kidney) & United States & ND & $\mathrm{L}$ \\
\hline $\mathrm{CA} 2$ & Ixodes neotomae & United States & $\mathbf{M}^{\prime}$ & $\mathbf{M}$ \\
\hline
\end{tabular}

${ }^{a}$ NS, no DraI restriction site; ND, not done. The DraI restriction fragment sizes were 204 and 49 bp for $B$. garinii (pattern $B^{\prime}$ ) and 206 and 49 bp for group VS116 (pattern $\mathrm{B}^{\prime \prime}$ ). Patterns $\mathrm{B}^{\prime}$ and $\mathrm{B}^{\prime \prime}$ were indistinguishable on gels.

${ }^{b} \mathrm{CSF}$, cerebrospinal fluid.

c Strain IpF was also called IPF, I. persulcatus, and $\mathbf{J} 1$.

${ }^{d}$ For strain NE57, only a small amount of DNA was available, which was kindly provided by J. Meyer

Tris- $\mathrm{HCl}, 1.5 \mathrm{mM} \mathrm{MgCl}, 50 \mathrm{mM} \mathrm{KCl}, 0.01 \%$ gelatin, $200 \mu \mathrm{M}$ dATP, $200 \mu \mathrm{M}$ dCTP, $200 \mu \mathrm{M}$ dGTP, $200 \mu \mathrm{M}$ dTTP, $1.25 \mathrm{U}$ of Taq polymerase (Amersham International, Amersham, England), each of the primers at a concentration of $1 \mu \mathrm{M}$, and 5 $\mu l$ of heated bacterial suspension or $10 \mathrm{ng}$ of DNA. The amplification reaction was carried out for 30 cycles with the following profile: denaturation at $94^{\circ} \mathrm{C}$ for $1 \mathrm{~min}$, annealing at $52^{\circ} \mathrm{C}$ for $1 \mathrm{~min}\left(56^{\circ} \mathrm{C}\right.$ for the $\mathrm{F} 63 \mathrm{~B}$ group), and extension at $72^{\circ} \mathrm{C}$ for $2 \mathrm{~min}$.

Digestion with MseI and DraI endonucleases and electrophoresis. Endonucleases MseI (New England Biolabs, Beverly, Mass.) and DraI (Amersham) were used to cleave PCR products $(20 \mathrm{U} / \mu \mathrm{g}$ of DNA) as recommended by the manufacturers. Electrophoresis was carried out in a $16 \%$ acrylamide- $0.8 \%$ bisacrylamide gel for $3 \mathrm{~h}$ at $100 \mathrm{~V}$. Marker V (Boehringer, Mannheim, Germany) was used as a molecular weight marker.
Cloning and DNA sequencing. Each PCR product (60 ng) was ligated in SmaI-cleaved pUC18 DNA by using a Surclone ligation kit (Pharmacia, Uppsala, Sweden). Ligation mixtures were transformed into $E$. coli $\mathrm{DH} 5 \alpha$, and transformants were selected on Luria-Bertani agar (26) containing $100 \mu \mathrm{g}$ of ampicillin per ml. Recombinant clones, each of which contained an insert of approximately $300 \mathrm{bp}$ after restriction by $E c o$ RI and PstI, were kept for further use.

The DNA sequence of the insert was determined by using a T7 sequencing kit (Pharmacia), a reverse primer (5'-AACAG CTATGACCATG-3'), and ${ }^{35}$ S-labeled dATP (Amersham). For each strain, two independent clones were sequenced, and the sequences of both strands were determined. Sequences were aligned and a phylogenetic tree was constructed by the neighbor-joining method (34) by using Clustal V software (19) and njplot software.

DNA-DNA reassociation. DNA was prepared, DNA relat- 


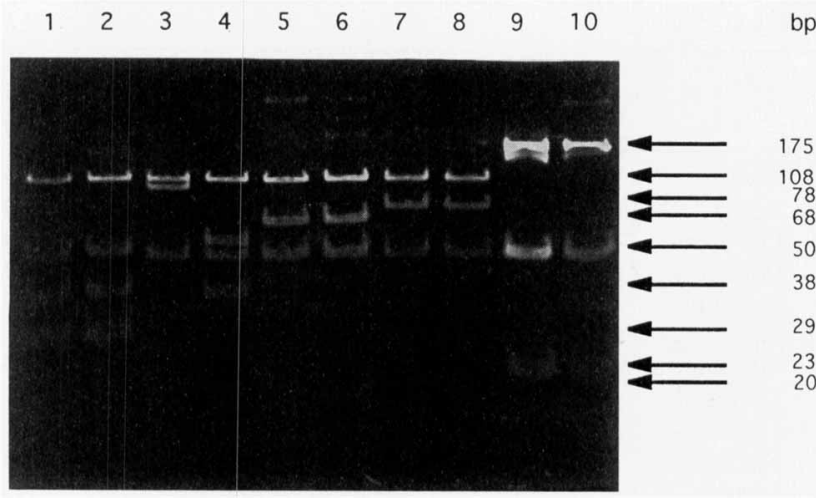

FIG. 1. MseI restriction patterns of Borrelia sensu lato strains. DNA was electrophoresed on a $16 \%$ acrylamide gel, stained with ethidium bromide, and UV illuminated. Lanes 1 and 2 pattern A produced by $B$. burgdorferi sensu stricto (strains Men 115 and $\mathrm{B} 31^{\mathrm{T}}$ ); lanes 3 and 4, patterns B and C produced by B. garinii (strains P526d and Ip89); lanes 5 and 6, pattern D produced by $B$. afzelii (strains $\mathrm{VS} 461^{\mathrm{T}}$ and $\mathrm{IpF}$ ); lanes 7 and 8 , pattern $\mathrm{E}$ produced by $B$. japonica (strains $\mathrm{HO}^{\mathrm{T}}{ }^{\mathrm{T}}$ and 0612 ); lanes 9 and 10, pattern $\mathrm{F}$ produced by group VS116 (strains VS116 and UK). Small fragments were difficult to distinguish on gels. Exact sizes were determined from the sequences.

edness values were determined, and levels of DNA divergence were estimated from $\Delta T_{m}$ values (14) by using the $S 1$ nuclease method as described previously (31) $\left(\Delta T_{m}\right.$ is the difference between the melting temperature of a homologous hybrid and the melting temperature of a heterologous hybrid).

Nucleotide sequence accession numbers. The $r r f-r r l$ spacer sequences of $18 \mathrm{~B}$. burgdorferi sensu lato strains have been assigned GenBank accession numbers L30127 (strain B31 ${ }^{\mathrm{T}}$ [T $=$ type strain]), L30121 (212), L30119 $\left(20047^{\mathrm{T}}\right), \quad$ L30130 (NT29), L30135 (VS461 $\left.{ }^{\mathrm{T}}\right)$, L30129 (J1), L30128 (HO14 $\left.{ }^{\mathrm{T}}\right)$, L30125 (Cow611C), L30131 (PotiB2), L30132 (PotiB3), L30134 (VS116), L30133 (UK), L30126 (DN127), L30122 (25015), L30124 (CA55), L30120 (21133), L30118 (19952), and L30123 (CA2).

\section{RESULTS}

PCR analysis. PCR amplification of the spacer region located between the $B$. burgdorferi sensu lato $r f$ and $r r l$ genes generated a fragment that was 226 to $266 \mathrm{bp}$ long, depending on the strain group. All strains except Japanese strain Ika2 produced this fragment. $B$. hermsii, $B$. parkeri, $B$. turicatae, $L$. interrogans, $S$. hyodysenteriae, and $E$. coli gave no amplification product.

RFLP of the $r r f-r r l$ spacer amplicon. After cleavage by MseI, the 99 PCR products were classified into 13 different patterns, designated patterns $A$ to $M$ (Fig. 1). Table 2 lists these patterns and shows the sizes of the MseI DNA fragments. All of the $B$. burgdorferi sensu stricto strains fell into pattern A. All $19 B$. afzelii strains fell into pattern $\mathrm{D}$, and the five $B$. japonica strains fell into pattern $\mathrm{E}$, whereas the $B$. garinii strains exhibited two different patterns (patterns B and C). Similar results were obtained after restriction by DraI (data not shown). The eight remaining $\mathrm{Mse}$ I patterns were produced by the 18 unclassified strains. The European strains could be divided into group VS116 (pattern F) and group PotiB2 (patterns $G$ and $H$ ). Pattern $\mathrm{H}$ (strain PotiB3) was similar to pattern E (B. japonica); the greatest difference was the presence of a 16-bp restriction fragment which was difficult to visualize. Patterns $\mathrm{E}$ and $\mathrm{H}$ could be differentiated easily after restriction by $D r a \mathrm{I}$. $B$.
TABLE 2. MseI restriction fragments of $r l-r f$ intergenic spacer amplicons

\begin{tabular}{lccl}
\hline \multicolumn{1}{c}{ Taxon(a) } & $\begin{array}{c}\text { Amplicon } \\
\text { size (bp) }\end{array}$ & $\begin{array}{c}\text { RFLP } \\
\text { pattern }\end{array}$ & $\begin{array}{c}\text { MseI restriction fragment } \\
\text { sizes (bp) }\end{array}$ \\
\hline B. burgdorferi & 254 & A & $108,51,38,29,28$ \\
B. garinii & & & \\
20047 & 253 & B & $108,95,50$ \\
$\quad$ NT29 & 253 & C & $108,57,50,38$ \\
B. afzelii & 246 & D & $108,68,50,20$ \\
B. japonica & 236 & E & $108,78,50$ \\
Group VS116 & 255 & F & $175,50,23,7$ \\
Group PotiB2 & & & \\
$\quad$ PotiB1 and PotiB2 & 257 & G & $108,81,39,29$ \\
$\quad$ PotiB3 & 255 & H & $108,79,52,16$ \\
Group DN127 & & & \\
$\quad$ DN127 & 257 & I & $108,51,38,33,27$ \\
California strains & 226 & J & $108,51,38,29$ \\
$\quad$ 25015 & 253 & K & $108,51,34,27,17,12,4$ \\
Group 21123 & & & \\
$\quad$ Group dentatus & 266 & L & $120,67,51,28$ \\
CA2 & 255 & M & $91,50,40,28,22,17,7$ \\
\hline
\end{tabular}

${ }^{a}$ Exact sizes were determined from the sequences.

japonica strains did not possess any DraI restriction site, while there were two DraI restriction sites in the PotiB3 amplicon, which produced three fragments (data not shown). The restriction fragment length polymorphism (RFLP) analysis revealed that there was broad heterogeneity in the unclassified American strains since five patterns (patterns I to $M$ ) were produced. Isolates DN127, 25015, and CA2 produced individual patterns (patterns I, K, and $\mathrm{M}$ ), the four California isolates obtained from Ixodes neotomae produced pattern $\mathrm{J}$, and the five strains obtained from Ixodes dentatus produced pattern L (Table 2).

Comparison of the nucleotide sequences of the $r r f-r r l$ spacer amplicon. Figure 2 shows the nucleotide sequences of the $r r f-r l$ amplicons obtained from 18 isolates. To assess the levels of homology within and between the different RFLP groups, we selected two isolates from each RFLP group for sequencing. No differences were observed in different sequences from the same isolate, excluding possible errors resulting from the use of the Taq polymerase during PCR. The level of identity among the sequences of the $r r f-r r l$ amplicons from the $18 B$. burgdorferi sensu lato strains was $60 \%$. It is interesting that the identity between two isolates belonging to each of the four previously described genomospecies was 99.2, 98, 100, and 99.6\% for $B$. burgdorferi sensu stricto, B. garinii, B. afzelii, and $B$. japonica, respectively. The sequences of the two group VS116 isolates (strains VS116 and UK) were $99.2 \%$ identical. The sequences of the two strains isolated from $I$. dentatus were 99.6\% identical. There was only $95.7 \%$ identity among the three group DN127 isolates, and there was also $95.7 \%$ identity among the three group PotiB2 isolates. A phylogenetic tree was deduced from the sequences (Fig. 3), and this tree showed the partition of the sequenced strains into nine branching groups.

DNA homology. The levels of DNA relatedness among $B$. burgdorferi, $B$. garinii, $B$. afzelii, and $B$. japonica have been published previously. None of the strains included in the four new RFLP groups (groups VS116, PotiB2, DN127, and 21123) were related to the type strains of $B$. garinii, $B$. afzelii, and $B$. japonica since the levels of relatedness were less than $70 \%$ and the $\Delta T_{m}$ values were more than $5^{\circ} \mathrm{C}$ (Table 3). None of the strains in groups VS116, PotiB2, and 21123 were related ( $<70 \%$ relatedness; $\Delta T_{m},>6^{\circ} \mathrm{C}$ ) to strain $\mathrm{B} 31$, the type strain of $B$. burgdorferi sensu stricto. 
Four of the unclassified strains (VS116, PotiB2, DN127, and 21123) were labelled for reverse hybridization experiments. The European strains constituted two homogeneous genomic groups that were not related to each other or to the other genomic species, as shown in Table 3. Group VS116 included strains VS116 and UK, which were 93 to $100 \%$ related to one another. Group PotiB2 included three Portuguese strains which were 92 to $100 \%$ related to each other. Among the American strains, two genomic groups could be distinguished. Genomic group DN127 included strain DN127 isolated from Ixodes pacificus, strain 25015 isolated from Ixodes dammini, and four California strains isolated from I. neotomae. These six strains were 79 to $100 \%$ related to each other, and the $\Delta T_{m}$ values were 0 to $3^{\circ} \mathrm{C}$. They were not related to other groups, but the levels of divergence in comparisons with isolates belonging to the $B$. burgdorferi genomospecies were borderline $\left(\Delta T_{m}, 5\right.$ to $\left.7^{\circ} \mathrm{C}\right)$. Genomic group 21123 was composed of five strains isolated from $I$. dentatus and one strain isolated from $I$. neotomae. Strains in this group were 73 to $100 \%$ related to strain 21123 and less than $68 \%$ related to members of other groups.

\section{DISCUSSION}

Among $B$. burgdorferi sensu lato strains four species have been described on the basis of DNA-DNA hybridization data. Reactivity with species-specific monoclonal antibodies provided phenotypic characteristics that were required for species descriptions. Ribotyping provided an identification system at the species level. DNA-DNA hybridization is presently the reference method used for species delineation (42). However, other less fastidious methods could be used to classify large strain collections, to identify Borrelia strains that occur in tick populations, or possibly in medical diagnosis. Methods based on PCR DNA amplification seem to be the methods of choice for these purposes. The organization of rRNA genes in Borrelia strains associated with Lyme borreliosis is unique among bacteria. There is a single $r r s$ gene and two copies each of the $r r l$ and $r f$ genes, which are tandemly duplicated $(18,38)$. The individual copies of the $r r l-r r f$ duplicate genes are separated by a 182 -bp spacer (38). We used this characteristic to design primers for the conserved ribosomal genes and to amplify the spacer between the two copies of the $r r l-r r f$ tandem repeat. Thus, the amplification product was specific for $B$. burgdorferi sensu lato, despite the lack of primer specificity. Given the unusual $r r$-rrf tandem genes, the duplicate genes attesting to gene rearrangements in the past, diversity among spacer sequences was expected. However, the results of ribotyping experiments performed with four distinct enzymes suggested that the flanking regions of ribosomal genes might be conserved enough to exhibit the level of variability that is mainly associated with genomic groups $(7,30)$. Otherwise, it has been shown that genetic transfers are very rare events in the genus Borrelia (15), and there is no insertion sequence which is known to introduce potential variability in the chromosome.

No amplification product was obtained from B. japonica Ika2, and this strain does not exhibit the same characteristic rRNA gene organization as other $B$. burgdorferi sensu lato strains (36). An analysis of the patterns obtained after restriction by $M s e I$ allowed us to recognize 13 patterns. Strains belonging to $B$. burgdorferi sensu stricto, $B$. afzelii, and $B$. japonica produced species-specific patterns $\mathrm{A}, \mathrm{D}$, and $\mathrm{E}$, respectively. Strains belonging to $B$. garinii could be divided into two RFLP groups (patterns $B$ and $C$ ). The group whose members produced pattern $\mathrm{B}$ included 26 of the $28 \mathrm{~B}$. garinii strains, including type strain 20047, and the group whose members produced pattern $\mathrm{C}$ included only strains Ip89 and NT29, which were obtained from Russia and Japan, respectively. A sequence analysis revealed only 5 nucleotide differences in the 253-bp amplicon, with one mutation located in an MseI site. It is interesting that $B$. garinii was also found to be the most heterogeneous species by ribotyping. Fukunaga et al. (17) found that Ip89 and NT29 produce an rRNA gene RFLP pattern distinct from the patterns produced by other $B$. garinii strains. However, the results of DNA relatedness studies allowed us to assign these strains to B. garinii (Table 3).

Since strains belonging to a previously defined species produced similar $\mathrm{Mse}$ I patterns, an analysis of the $\mathrm{MseI}$ restriction polymorphism patterns of PCR-amplified products provided a simple tool for assigning unknown strains to genomic groups. On the basis of the results of an analysis of the patterns obtained after cleavage by $\mathrm{MseI}$ and DraI separately, two groups composed of European strains and two groups composed of American strains were identified. DNA-DNA hybridization results confirmed assignment of strains that produced the same RFLP pattern to the same new genomic group.

The first European genomic group, group VS116, included three strains, VS116, UK, and NE57. VS116 and NE57 have both been reported to be putative representatives of a new genomic group on the basis of the electrophoretic mobilities of OspA and OspB (28) and on the basis of chromosomal DNA RFLP patterns (16), respectively. The results of DNA relatedness and $r f-r r l$ spacer RFLP experiments allowed us to place these strains in the same genomic group. The second European group, group PotiB2, contained three strains which are closely related as determined by DNA-DNA hybridization but are quite different in their $r r f-r r l$ nucleotides sequences. It is interesting that strain PotiB3, which differed in its restriction polymorphism pattern (pattern $\mathrm{H}$ ), was isolated from the same individual Ixodes ricinus tick as strain PotiB2 (pattern G).

On the basis of DNA relatedness data, American strains could be divided into two additional genomic groups. The results of the $r f-r r l$ spacer RFLP experiment supported the heterogeneity of these organisms. Until now, American $B$. burgdorferi strains have been considered to be very homogeneous, and $B$. burgdorferi sensu stricto was the only Lyme disease species known to occur in the United States. However, some strains have been described as atypical. Strain DN127 was reported to be an unusual strain that did not react with monoclonal antibodies to OspA and OspB and produced an abundant $25-\mathrm{kDa}$ protein $(10,22)$. This strain did not give an amplification product with primers flanking the osp operon, thus behaving differently than strains belonging to $B$. burgdorferi sensu stricto (35). The results of an arbitrarily primed PCR (43) and restriction site polymorphism in the $16 \mathrm{~S}$ rRNA genes (32) also distinguished strain DN127 from other phyletic groups.

The results of a study of the variability of the osp operon led Marconi et al. to propose that there is a peripheral relationship between American strain 25015 and $B$. burgdorferi sensu stricto (24). The results of a comparison of $o s p A$ sequences led Dykhuizen et al. to not classify strains 25015 and 19857 as members of the three major species (15). An analysis of RFLP of the $83-\mathrm{kDa}$ antigen gene revealed that two American strains, DN127 and 25015, did not cluster with other American isolates $(45,46)$. The OspA protein of these strains has a molecular weight of about 32,000 , in contrast to a molecular weight of 31,000 for the OspA of B. burgdorferi sensu stricto (3, 10). Moreover, strain 25015 has been described as an infectious but nonpathogenic isolate (3). DNA-DNA hybridization results have shown that strains DN127 and 25015 belong to the 


\begin{tabular}{|c|}
\hline $\mathrm{B} 31^{\mathrm{T}}$ \\
\hline 212 \\
\hline PotiB2 \\
\hline PotiB3 \\
\hline VS $461^{\mathrm{T}}$ \\
\hline J1 \\
\hline $20047^{\mathrm{T}}$ \\
\hline NT29 \\
\hline Cow611C \\
\hline $\mathrm{HO} 4^{\mathrm{T}}$ \\
\hline VS 116 \\
\hline UK \\
\hline CA5 5 \\
\hline DN127 \\
\hline 25015 \\
\hline $\mathrm{CA} 2$ \\
\hline 21133 \\
\hline 19952 \\
\hline$B 31^{T}$ \\
\hline 212 \\
\hline PotiB2 \\
\hline PotiB3 \\
\hline VS $461^{\mathrm{T}}$ \\
\hline J1 \\
\hline $20047 \mathrm{~T}$ \\
\hline NT29 \\
\hline Cow611C \\
\hline $\mathrm{HO} 14^{\mathrm{T}}$ \\
\hline VS 116 \\
\hline UK \\
\hline CA55 \\
\hline DN127 \\
\hline 25015 \\
\hline $\mathrm{CA} 2$ \\
\hline 21133 \\
\hline 19952 \\
\hline $\mathrm{B} 31^{\mathrm{T}}$ \\
\hline 212 \\
\hline PotiB2 \\
\hline PotiB3 \\
\hline VS $461^{\mathrm{T}}$ \\
\hline J1 \\
\hline $20047^{\mathrm{T}}$ \\
\hline NT29 \\
\hline Cow $611 \mathrm{C}$ \\
\hline $\mathrm{HO} 4^{\mathrm{T}}$ \\
\hline VS 116 \\
\hline UK \\
\hline CA55 \\
\hline DN127 \\
\hline 25015 \\
\hline $\mathrm{CA} 2$ \\
\hline 21133 \\
\hline 19952 \\
\hline
\end{tabular}

$5 \mathrm{~S} 3^{\prime}$ end

CTGCGAGTTCGCGGGAGAGTAGGTTATTGCCAGGGTTTTTATTTTTATAC CTGCGAGTTCGCGGGAGAGTAGGTTATTGCCAGGGTTTTTATTTTTATAC CTGCGAGTTCGCGGGAGAGTAGGTTATTGCCAGGGTTTTTTATTTTATAC CTGCGAGTTCGCGGGAGAGTAGGTTATTGCCAGGGTTTTTTATTTTGTAC CTGCGAGTTCGCGGGAGAGTAAGTTATTGCCAGGGTTTTTATTTT-ATAC CTGCGAGTTCGCGGGAGAGTAAGTTATTGCCAGGGTTTTTATTTT-ATAC CTGCGAGTTCGCGGGAGAGTAAGTTGTTGCCAGGGTTTTTGTTTT-ATAC CTGCGAGTTCGCGGGAGAGTAAGTTATTGCCAGGGTTTTTATTTT-ATAC CTGCGAGTTCGCGGGAGAGTAAGTTATTGCCCGGGTTTTTA-TTTTGTAT CTGCGAGTTCGCGGGAGAGTAAGTTATTGCCAGGGTTTTTA-TTTTGTAT CTGAGAGTTCGCGGGAGAGTAAGTTATTGCCAGGGTTTTTATTTT-GTAA CTGCGAGTTCGCGGGAGAGTAAGTTATTGCCAGGGTTTTTATTTT-GTAC CTGCGAGTTCGCGGGAGAGTAGGTTATTGCCAGGGTTTTTATTTTTATAT CTGCGAGTTCGCGGGAGAGTAGGTTATTGCCAGGGTTTTTATTTTTATAT CTGCGAGTTCGCGGGAGAGTAAGTTATTGCCAGGGTTTTTATTTTTATAT CTGCGAGTTCGCGGGAGAGTAGGTTATTGCCAGGGTTTTTATTTTT-TGC CTGCGAGTTCGCGGGAGAGTAGGTTATTGCCAGGGTTTTTATTTTTACGC CTGCGAGTTCGCGGGAGAGTAGGTTATTGCCAGGGTTTTTATTTTTACGC

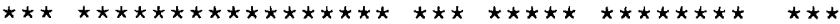

TTTAAACTTTGATTTTATTTTT-ATGTTTTTT-AAATATT----GGTGTT TTTAAACTTTGATTTTATTTTT-ATGTTTTTT-AAATATT----GGTGTT TTCAAATCTTGAATTTATTTTTTATATTTTTTTAAATGTTTATT----TT TTCAAATCTTGAATTTATTTTTTATGTTTT--TAAATGTTTATT----TT TTTAAACCTTGAATTTATTTTTTA--_-----AATGTTTAT--AT-TA TTTAAACCTTGAATTTATTTTTTA--_------AATGTTTAT--AT-TA TTTAAACATTGATTTTATTTTTTATGTTTTTA--GATGTTCAT--GT-TTTTAAACATTGATTTTATTTTTTATGTTTTTA--GATGTTCAT--GT-TTTTAAGCCTTGATTTTATTTTT-ATA-_-_-_-_-_-_--GTA TTTAAGCCTTGATTTTATTTTT-ATA------_---------GTA TTTAAACCTTAAATTTATTTTTTATATTTTTT-TAATGTTTAT--GT-TTTTAAACCTTAAATTTATTTTTTATATTTTTT-TAATGTTCAT--GT-T-


TTTAAATCTTGATTTTATTTT--ATGTTTTTT-AAATGTTTGTTAGTTTT TTTAAATCTTGATTTTATTTT--ATGTTTTTT-AAATG----TTAGTGTT TTTAAGTCTTAATTTTATTTTT-ATGTTTCTTTAA-----TATTAGTATT -TTAAGTCTTGATTTTATATTT-ATGTTTCTTAAA-----TATTAGCGTT CTTAAGTCTTGATTTTATATTT-ATGTTTCTTAAA-----TATTAGCGTT

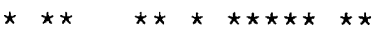

TTTGAATGTGTTGTTTAAATAA-CATAAAAAATAGAATATAT--ATTGAC TTTGAATGTGTTGTTTAAATAA-CATAAAAA-TAAAATATAT--ATTGAC TTTGAATGTTTGATTTAAAAAAATATAAAAAATAAAATAGAT--ATTGAC TTTAAATCAAACATTCAAAAAAATATAAAAAATAAAATAGAT--ATTGAC TTTGAATAAAACATTCAAATAA-TATAAAAAATAATATATAT--ATTGAC TTTGAATAAAACATTCAAATAA-TATAAAAAATAATATATAT--ATTGAC TTTGAATGTTTTATTCAAATAA-TATAAAAAATAAAATATAT--ATTGAC TTTGAATGTTTTATTTAAATAA-TATAAAAAATAAAATATAT--ATTGAC TTTGAATAAAACATTCAAATAC-TATAAAAA-TAAAATAGAT--ATTGAC TTTGAATAAAACATTCAAATAC-TATAAAAA-TAAAATAGAT--ATTGAC TTTGAATGTTTTATTCAAATAA-TGTAAAAAATAAAATAGAT--ATTGAC TTTGAATGTTTTATTCAAATAA-TGTAAAAAATAAAATAGAT--ATTGAC -------TTATTTAAATAA-CATAAAAAATAAAATATAT--ATTGAC TTTGAATGTGTTATTTAAATAA-CATAAAAAATAAAATATAT--ATTGAC TTTTAATGTATTATTTAATTAA-CATAAAAAATAAAATATAT--ATTGAC TTTGAATGTGTTATTTAAATAG-CGTAAAAAATAAAATATATATATTGAC TTTGGATGTATTATTTAGGTAG-CATAAAAAATAAAATATATG--TTGAC TTTGGATGTATTATTTAGGTAG-CATAAAAAATAAAATATATG--TTGAC

FIG. 2. Nucleotide sequences of the $r f-r r l$ spacer amplicons of $B$. burgdorferi sensu lato isolates. Gaps were introduced to obtain maximum levels of homology. The $3^{\prime}$ end of the $r f$ gene and the $5^{\prime}$ end of the $r l$ gene are indicated by boldface type. 


\begin{tabular}{|c|c|}
\hline $\mathrm{B} 31^{\mathrm{T}}$ & ATGTATTAAACAAA----GATATAT-------ATTATTTTATGTTGTAT \\
\hline 212 & ATGTATTAAACAAA----GATATAT-------ATTATTTTATGTTGTAT \\
\hline PotiB2 & ATGGATTAAACAAA----GATATAT--------ATTATTCTATGTTGCAT \\
\hline PotiB3 & ATGGATTAAACAAA----GATATAT--------ATTATTCTATGTTGCAT \\
\hline VS $461^{\mathrm{T}}$ & ATGGATTAAACAAA----GATATAT-------ATTATTCTATGTTGTAT \\
\hline $\mathrm{J} 1$ & ATGGATTAAACAAA----GATATAT-------ATTATTCTATGTTGTAT \\
\hline $20047^{\mathrm{T}}$ & ATGGATTAAACAAA----GATATAT--------ATTATTCTATGTTGTAT \\
\hline NT29 & ATGGATTAAACAAA----GATATAT--------ATTATTCTATGTTGCAT \\
\hline Cow611C & ATGGGTTAAACAAA----GATATAT--------ATTATTCTATGTTACAT \\
\hline $\mathrm{HO} 4^{\mathrm{T}}$ & ATGGGTTAAACAAA----GATATAT--------ATTATTCTATGTTACAT \\
\hline VS116 & ATGGATTGAACAAA---AGATATAT--------ATTATTTTATGTTGCAT \\
\hline UK & ATGGATTGAACAAA---AGATATAT--------ATTATTTTATGTTGCAT \\
\hline CA55 & ATGGATTAAACAAA----GATATAT-------ATTATTTTATGTTGTAT \\
\hline DN127 & ATGGATTAAACAAA----GATATAT--------ATTATTTTATGTTGCGT \\
\hline 25015 & ACGGATTAAACAAA----GATATAT--------ATTATTTTATGTTGCAT \\
\hline $\mathrm{CA} 2$ & ATGGATTAAACAAAGATATATAT---------TAATTTATGTTGCAT \\
\hline 21133 & ATGGATTAAACATAGATAGATATATGTATCTCTATTATTTTATGCTGCAT \\
\hline \multirow[t]{2}{*}{19952} & ATGGATTAAACATAGATAGATATATGTATCTCTATTATTTTATGCTGCAT \\
\hline &  \\
\hline $\mathrm{B} 31^{\mathrm{T}}$ & AAATAAATTGGCAAAATAGAGATGGAAGATAAAAATATGGTCAAAGTAAT \\
\hline 212 & AAATAAATTGGCAAAATAGAGATGGAAGATAAAAATATGGTCAAAGTAAT \\
\hline PotiB2 & AAACAAATTGGCAAAGTAGAGATGGAAGATAAAAATATGGTCAAAGTAAT \\
\hline PotiB3 & AAACAAATTGGCAAAGTAGAGATGGAAGATAAAAATATGGTCAAAGTAAT \\
\hline VS $461^{\mathrm{T}}$ & AAACAAATTGGCAAAATAGAGATGGAAGATAAAAATATGGTCAAAGTAAT \\
\hline $\mathrm{J} 1$ & AAACAAATTGGCAAAATAGAGATGGAAGATAAAAATATGGTCAAAGTAAT \\
\hline $20047^{\mathrm{T}}$ & AAACAAATTGGCAAAATAGAGATGGAAGATAAAAATATGGTCAAAGTAAT \\
\hline NT29 & AAGCAAATTGGCAAAATAGAGATGGAAGATAAAAATATGGTCAAAGTAAT \\
\hline Cow611C & AAACAAATTGGCAAAGTAGAGATGGAAGATAAAAATATGGTCAAAGTAAT \\
\hline $\mathrm{HO} 14^{\mathrm{T}}$ & AAACAAATTGGCAAAGTAGAGATGGAAGATAAAAATATGGTCAAAGTAAT \\
\hline VS116 & AAACAAATTGGCAAAATAGAGATGGAAGATAAAAATATGGTCAAAGTAAT \\
\hline UK & AAACAAATTGGCAAAATAGAGATGGAAGATAAAAATATGGTCAAAGTAAT \\
\hline CA55 & AAACAAATTGGCAAAATAGAGATGGAAGATAAAAATATGGTCAAAGTAAT \\
\hline DN127 & AAACAAATTGGCAAAATAGAGATGGAAGATAAAAATATGGTCAAAGTAAT \\
\hline 25015 & AAACAAATTGGCAAAATAGAGATGGAAGATAAAAATATGGTCAAAGTAAT \\
\hline CA2 & AAACAAATTGGCAAAATAGAGATGGAAGATAAAAATATGGTCAAAGTAAT \\
\hline 21133 & AAGCAAATTGGCAAAATAGAGATGGAAGATAAAAATATGGTCAAAGTAAT \\
\hline & AAGCAAATTGGCAAAATAGAGCTGGAAGATAAAAATATGGTCAAAGTAAT \\
\hline & 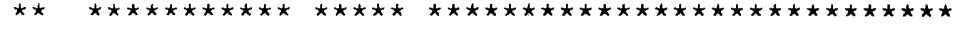 \\
\hline
\end{tabular}

$\mathrm{B} 31^{\mathrm{T}}$

212

PotiB2

PotiB3

VS $461^{\mathrm{T}}$

J1

$20047^{\mathrm{T}}$

NT29

Cow $611 \mathrm{C}$

HO1 $4^{\mathrm{T}}$

VS 116

UK

CA55

DN127

25015

CA2

21133

19952
AAGAGTCTATGGTGAATGCCTAGGA AAGAGTCTATGGTGAATGCCTAGGA AAGAGTCTATGGTGAATGCCTAGGA AAGAGTCTATGGTGAATGCCTAGGA AAGAGTCTATGGTGAATGCCTAGGA AAGAGTCTATGGTGAATGCCTAGGA AAGAGTCTATGGTGAATGCCTAGGA AAGAGTCTATGGTGAATGCCTAGGA AAGAGTCTATGGTGAATGCCTAGGA AAGAGTCTATGGTGAATGCCTAGGA AAGAGTCTATGGTGAATGCCTAGGA AAGAGTCTATGGTGAATGCCTAGGA AAGAGTCTATGGTGAATGCCTAGGA AAGAGTCTATGGTGAATGCCTAGGA AAGAGTCTATGGTGAATGCCTAGGA AAGAGTCTATGGTGAATGCCTAGGG AAGAGTCTATGGTGAATGCCTAGGA AAGAGTCTATGGTGAATGCCTAGGA

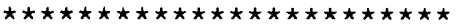
23 S 5 'end

FIG. 2 -Continued. 


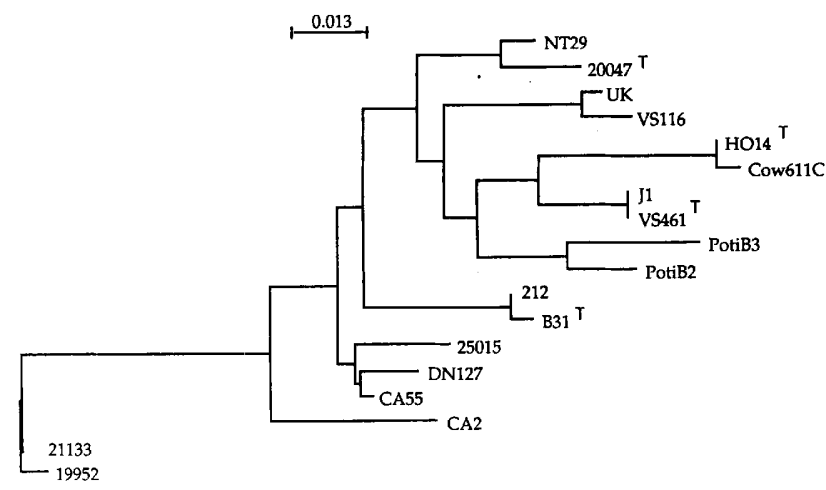

FIG. 3. Phylogenetic tree determined from the DNA sequences of rrl-rrf spacer amplicons. same genomic group, group DN127, along with four California strains isolated from I. neotomae (6). The protein profiles of these California isolates differed markedly from the profiles of the eastern United States isolates (12). The enzootic cycle involving $I$. neotomae has been reported to be quite different from the cycles involving I. pacificus or Ixodes scapularis (12).

The second American genomic group characterized in this study, group 21123, comprised five strains isolated from cottontail rabbits and $I$. dentatus ticks. These strains did not react with $B$. burgdorferi sensu stricto specific monoclonal antibody H3TS (4). Despite differences in levels of DNA relatedness between strains 19865 and 19941 and B. burgdorferi sensu stricto reference strain $\mathrm{B} 31^{\mathrm{T}}$ (61 and $64 \%$, respectively), Anderson et al. did not conclude that these organisms diverged at the species level (4). Our previous results clearly showed that these strains belong to a genomic group that is distinct from B. burgdorferi sensu stricto (6). Group 21123 appears to be less closely related to $B$. burgdorferi sensu stricto than group DN127 is when both genetic and epidemiological features are considered. DNA-DNA hybridization experiments gave borderline results with the six strains belonging to group DN127,

TABLE 3. Levels of DNA relatedness for B. burgdorferi sensu lato strains used in this study

\begin{tabular}{|c|c|c|c|c|c|c|c|c|}
\hline \multirow[b]{2}{*}{ Isolate } & \multicolumn{8}{|c|}{ Level of DNA relatedness (relative binding ratio) with labelled DNA from ${ }^{a}$ : } \\
\hline & $\begin{array}{l}\text { Strain } \\
\text { B31 }\end{array}$ & $\begin{array}{l}\text { Strain } \\
20047^{\mathrm{T}}\end{array}$ & $\begin{array}{c}\text { Strain } \\
\text { VS461 }^{\mathbf{T}}\end{array}$ & $\begin{array}{l}\text { Strain } \\
\text { Ika2 }\end{array}$ & $\begin{array}{l}\text { Strain } \\
\text { VS116 }\end{array}$ & $\begin{array}{l}\text { Strain } \\
\text { PotiB2 }\end{array}$ & $\begin{array}{l}\text { Strain } \\
\text { DN127 }\end{array}$ & $\begin{array}{l}\text { Strain } \\
21123\end{array}$ \\
\hline \multicolumn{9}{|l|}{ B. burgdorferi } \\
\hline $\begin{array}{l}\text { IP1 } \\
\text { Z118 }\end{array}$ & & 46 & & & & & $57(5)$ & $64(8)$ \\
\hline $\mathrm{B} 31^{\mathrm{T}}$ & $100(0)^{b, c}$ & $55(8)^{c}$ & $48(9)^{c}$ & & $54(7)$ & 57 & $59(7)$ & $70(6)$ \\
\hline \multicolumn{9}{|l|}{ B. garinii } \\
\hline $20047^{\mathrm{T}}$ & $51(10)^{c}$ & $100(0)^{c}$ & $65(7)^{c}$ & & 60 & $62(7)$ & 45 & $62(8)$ \\
\hline FujiP2 & 58 & 100 & $68(8)$ & & & & & \\
\hline HP13 & 60 & $78(1)$ & $73(7)$ & & & & & \\
\hline NT29 & 58 & $86(3)$ & $66(6)$ & & & 62 & & \\
\hline Ip89 & & 84 & 67 & & & & & \\
\hline B. afzelii VS461 ${ }^{\mathrm{T}}$ & $51^{c}$ & $62(7)^{c}$ & $100(0)^{c}$ & & 60 & $58(8)$ & $39(9)$ & $50(9)$ \\
\hline \multicolumn{9}{|l|}{ B. japonica } \\
\hline Ika2 & $58^{c}$ & $58^{c}$ & $65(7)^{c}$ & $100(0)^{c}$ & & $64(8)$ & 57 & \\
\hline Cow611C & & & & & & & 53 & \\
\hline \multicolumn{9}{|l|}{ Group VS116 } \\
\hline VS116 & $54(7)$ & $56(7)$ & $64(8)$ & 58 & $100(0)$ & & 46 & 60 \\
\hline UK & $65(8)$ & 63 & 70 & & $93(0)$ & 60 & & \\
\hline \multicolumn{9}{|l|}{ Group PotiB2 } \\
\hline PotiB1 & $53(9)$ & & & & 54 & 98 & 26 & \\
\hline PotiB2 & & & & & 56 & $100(0)$ & & \\
\hline PotiB3 & 44 & & & & 53 & $92(0)$ & & 58 \\
\hline \multicolumn{9}{|l|}{ Group DN127 } \\
\hline DN127 & $67(6)^{c}$ & $52(8)$ & 61 & $52(7)$ & & 54 & $100(0)^{c}$ & $64(7)^{c}$ \\
\hline CA118 & $72(6)^{c}$ & & & & & & $79(0)^{c}$ & \\
\hline CA128 & $68(5)^{c}$ & & & & 52 & 54 & $80(0)^{c}$ & $63(7)^{c}$ \\
\hline CA55 & $72(6)^{c}$ & & & & & & $80(0)^{c}$ & $62(6)^{c}$ \\
\hline CA127 & $73(7)^{c}$ & & & & & & $95^{c}$ & \\
\hline 25015 & $68(6)^{c}$ & & & & & & $83(3)^{c}$ & $64^{c}$ \\
\hline \multicolumn{9}{|l|}{ Group 21123} \\
\hline 21123 & & & & $51(8)$ & & 55 & $66^{c}$ & $100(0)^{c}$ \\
\hline 21133 & $63^{c}$ & & & & & & $56(8)^{c}$ & $86(2)^{c}$ \\
\hline 19952 & $59(6)^{c}$ & 52 & 54 & & & & $60^{c}$ & $87(1)^{c}$ \\
\hline 19865 & $68(7)$ & 50 & 64 & & & & 59 & $86(2)$ \\
\hline 19857 & & & & & & & & $82(2)$ \\
\hline $\mathrm{CA} 2$ & $67(7)$ & 57 & 60 & $56(8)$ & & 56 & $64(7)$ & $73(5)$ \\
\hline
\end{tabular}

${ }^{a}$ Relative binding ratios were determined at $60^{\circ} \mathrm{C}$. The values in parentheses are $\Delta T_{m}$ values (in degrees Celsius). For more data on levels of DNA relatedness to B. burgdorferi, B. garinii, and B. afzelii (formerly group VS461) see reference 7, and for data on levels of DNA relatedness to B. japonica (formerly group F63B) see reference 30 .

${ }^{b}$ The values in boldface type are homologous hybridization results.

${ }^{c}$ Previously published data $(6,7,30)$. 
since the levels of relatedness to $\mathrm{B} 31^{\mathrm{T}}$ were 68 to $73 \%$ and the $\Delta T_{m}$ values were 5 to $7^{\circ} \mathrm{C}$. $I$. dentatus ticks feed almost exclusively on rabbits and birds and rarely on humans. Borrelia strains similar to those obtained from $I$. dentatus have never been isolated from humans, which suggests that group 21123 strains may be nonpathogenic for humans. Our data confirm the two new American genomic groups proposed on the basis of the results of an $\mathrm{fla}$ gene-based PCR assay (6). Groups DN127 and 21123 were found to be related to $B$. burgdorferi sensu stricto, although they are distinct from this species as determined by DNA-DNA hybridization (6). The status of strain CA2, which was isolated from $I$. neotomae, remains unclear. This strain was not related to $B$. burgdorferi sensu stricto or to group DN127, in contrast to other strains obtained from I. neotomae. Strain CA2 was related to strain 21123 from I. dentatus, but the level of relatedness was borderline. Whereas the rrl-rrf DNA sequences of two other strains obtained from $I$. dentatus (strains 21133 and 19952) exhibited $99.6 \%$ identity, strain CA2 exhibited only $87.2 \%$ identity with these two strains and $79.6 \%$ identity with strain CA55 from $I$. neotomae. Complementary studies would be needed to assign strain CA2 definitively to genomic group 21123 .

The results of comparison of $r f-r r l$ spacer sequences are not suitable for drawing phylogenetic conclusions. However, it is interesting that the branching pattern revealed, on one side, $B$. burgdorferi sensu stricto and the other two American genomic groups and, on the other side, five other branches, each of which corresponded to a genomic group. Interestingly, genomic group VS116, $B$. japonica, $B$. afzelii, and genomic group PotiB2 seem to have evolved from $B$. garinii. This hypothesis was deduced previously from a comparison of $B$. burgdorferi sensu stricto, $B$. garinii, and $B$. afzelii osp $C$ sequences (40).

The existence of two new genomic groups in the United States could be related to different enzootic maintenance cycles involving a broader vector and host spectrum. The importance of these new groups in terms of pathogenicity for humans is not known yet.

Our results indicate that $r r f-r r l$ spacer RFLP analysis is a simple and useful tool for assessing the genetic diversity of Borrelia strains associated with Lyme borreliosis. This technique could have applications in epidemiological and medical fields.

\section{ACKNOWLEDGMENTS}

We thank J. Anderson, E. Asbrink, A. Aeschlimann, S. Bergström, K. J. Cann, M. Fukunaga, L. Gern, E. Isogai, M. Janda, R. C. Johnson, C. Kodner, R. Lane, R. T. Marconi, T. Masuzawa, F. Milward, C. Perez-Eid, O. Péter, D. Ralph, V. Sambri, A. Vogt, and B. Wilske for supplying strains, M. Gouy and J. Thioulouse for supplying the njplot software, and I. Saint Girons and I. Old for critical reading of the manuscript.

This work was supported by a grant from the G. Harold and Leila Y. Mathers Charitable Foundation.

\section{REFERENCES}

1. Adam, T., G. S. Gassmann, C. Rasiah, and U. B. Göbel. 1991. Phenotypic and genotypic analysis of Borrelia burgdorferi isolates from various sources. Infect. Immun. 59:2579-2585.

2. Amouriaux, P., M. Assous, D. Margarita, G. Baranton, and I. Saint Girons. 1993. Polymerase chain reaction with the $30 \mathrm{~kb}$ circular plasmid of Borrelia burgdorferi $\mathrm{B} 31$ as a target for detection of the Lyme borreliosis agents in cerebrospinal fluid. Res. Microbiol. 144:211-219.

3. Anderson, J. F., S. W. Barthold, and L. A. Magnarelli. 1990. Infectious but nonpathogenic isolate of Borrelia burgdorferi. J. Clin. Microbiol. 28:2693-2699.
4. Anderson, J. F., L. A. Magnarelli, B. LeFebvre, T. G. Andreadis, J. B. McAninch, G. C. Perng, and R. C. Johnson. 1989. Antigenically variable Borrelia burgdorferi isolated from cottontail rabbits and Ixodes dentatus in rural and urban areas. J. Clin. Microbiol. 27:13-20.

5. Assous, M. V., D. Postic, G. Paul, P. Névot, and G. Baranton. 1993. Western blot analysis of sera from Lyme borreliosis patients according to the genomic species of the Borrelia strains used as antigens. Eur. J. Clin. Microbiol. Infect. Dis. 12:261-268.

6. Assous, M. V., D. Postic, G. Paul, P. Névot, and G. Baranton. 1994. Individualisation of two genomic groups among American Borrelia burgdorferi sensu lato strains. FEMS Microbiol. Lett. 121:93-98.

7. Baranton, G., D. Postic, I. Saint Girons, P. Boerlin, J. C. Piffaretti, M. Assous, and P. A. D. Grimont. 1992. Delineation of Borrelia burgdorferi sensu stricto, Borrelia garinii sp. nov., and group VS461 associated with Lyme borreliosis. Int. J. Syst. Bacteriol. 42:378383.

8. Barbour, A. 1989. Classification of Borrelia burgdorferi on the basis of plasmid profiles. Zentralbl. Bakteriol. Suppl. 18:1-7.

9. Belfaiza, J., D. Postic, E. Bellenger, G. Baranton, and I. Saint Girons. 1993. Genomic fingerprinting of Borrelia burgdorferi sensu lato by pulsed-field gel electrophoresis. J. Clin. Microbiol. 31: 2873-2877.

10. Bissett, M. L., and W. Hill. 1987. Characterization of Borrelia burgdorferi strains isolated from Ixodes pacificus ticks in California. J. Clin. Microbiol. 25:2296-2301.

11. Boerlin, P., O. Péter, A. G. Bretz, D. Postic, G. Baranton, and J. C. Piffaretti. 1992. Population genetic analysis of Borrelia burgdorferi isolates by multilocus enzyme electrophoresis. Infect. Immun. 60:1677-1683.

12. Brown, R. N., and R. S. Lane. 1992. Lyme disease in California-a novel enzootic transmission cycle of Borrelia burgdorferi. Science 256:1439-1442.

13. Canica, M. M., F. Nato, L. du Merle, J. C. Mazie, G. Baranton, and D. Postic. 1993. Monoclonal antibodies for identification of Borrelia afzelii sp. nov. associated with late cutaneous manifestations of Lyme borreliosis. Scand. J. Infect. Dis. 25:441-448.

14. Crosa, J. H., D. J. Brenner, and F. Falkow. 1973. Use of a single-strand-specific nuclease for analysis of bacterial and plasmid deoxyribonucleic acid homo- and heteroduplexes. J. Bacteriol. 115:904-911.

15. Dykhuizen, D. E., D. S. Polin, J. J. Dunn, B. Wilske, V. PreacMursic, R. J. Dattwyler, and B. J. Luft. 1993. Borrelia burgdorferi is clonal: implications for taxonomy and vaccine development. Proc. Natl. Acad. Sci. USA 90:10163-10167.

16. Filipuzzi-Jenny, E., M. Blot, N. Schmid-Berger, J. Meister-Turner, and J. Meyer. 1993. Genetic diversity among Borrelia burgdorferi isolates: more than three genospecies? Res. Microbiol. 144:295304.

17. Fukunaga, M., M. Sohnaka, M. Nakao, and K. Miyamoto. 1993. Evaluation of genetic divergence of borrelial isolates from Lyme disease patients in Hokkaido, Japan, by rRNA gene probes. J. Clin. Microbiol. 31:2044-2048.

18. Fukunaga, M., Y. Yanagihara, and M. Sohnaka. 1992. The 23S/5S ribosomal RNA genes $(r r / / r f)$ are separate from the $16 \mathrm{~S}$ ribosomal RNA gene ( $r r s$ ) in Borrelia burgdorferi, the aetiological agent of Lyme disease. J. Gen. Microbiol. 138:871-877.

19. Higgins, D. G., and R. Sharp. 1989. Fast and sensitive multiple sequence alignments on a microcomputer. CABIOS 5:151-153.

20. Johnson, R. C., G. P. Schmid, F. W. Hyde, A. G. Steigerwalt, and D. J. Brenner. 1984. Borrelia burgdorferi sp. nov.: etiological agent of Lyme disease. Int. J. Syst. Bacteriol. 34:496-497.

21. Kawabata, H., T. Masuzawa, and Y. Yanagihara. 1993. Genomic analysis of Borrelia japonica sp. nov. isolated from Ixodes ovatus in Japan. Microbiol. Immunol. 37:843-848.

22. Kurashige, S., M. Bissett, and L. Oshiro. 1990. Characterization of a tick isolate of Borrelia burgdorferi that possesses a major lowmolecular-weight surface protein. J. Clin. Microbiol. 28:13621366.

23. LeFebvre, R. B., G. C. Perng, and R. C. Johnson. 1989. Characterization of Borrelia burgdorferi isolates by restriction endonuclease analysis and DNA hybridization. J. Clin. Microbiol. 27:636639. 
24. Marconi, R. T., M. E. Konkel, and C. F. Garon. 1993. Variability of $o s p$ genes and gene products among species of Lyme disease spirochetes. Infect. Immun. 61:2611-2617.

25. Marconi, R. T., L. Lubke, W. Hauglum, and C. F. Garon. 1992. Species-specific identification of and distinction between Borrelia burgdorferi genomic groups by using 16S rRNA-directed oligonucleotide probes. J. Clin. Microbiol. 30:628-632.

26. Miller, J. H. 1972. Experiments in molecular genetics. Cold Spring Harbor Laboratory Press, Cold Spring Harbor, N.Y.

27. Persing, D. H., S. R. Telford, A. Speilman, and S. W. Barthold. 1990. Detection of Borrelia burgdorferi infection in Ixodes dammini with the polymerase chain reaction. J. Clin. Microbiol. 28:566-572.

28. Péter, O., and A. G. Bretz. 1992. Polymorphism of outer surface proteins of Borrelia burgdorferi as a tool for classification. Zentralbl. Bakteriol. 277:28-33.

29. Picken, R. N. 1992. Polymerase chain reaction primers and probes derived from flagellin gene sequences for specific detection of the agents of Lyme disease and North American relapsing fever. J. Clin. Microbiol. 30:99-114.

30. Postic, D., J. Belfaiza, E. Isogai, I. Saint Girons, P. A. D. Grimont, and G. Baranton. 1993. A new genomic species in Borrelia burgdorferi sensu lato isolated from Japanese ticks. Res. Microbiol. 144:467-473.

31. Postic, D., C. Edlinger, C. Richaud, F. Grimont, Y. Dufresne, P. Perolat, G. Baranton, and P. A. D. Grimont. 1990. Two genomic species in Borrelia burgdorferi. Res. Microbiol. 141:465-475.

32. Ralph, D., D. Postic, G. Baranton, C. Pretzman, and M. McClelland. 1993. Species of Borrelia distinguished by restriction site polymorphisms in 16S rRNA genes. FEMS Microbiol. Lett. 111: 239-243.

33. Rosa, P. A., D. Hogan, and T. G. Schwan. 1991. Polymerase chain reaction analyses identify two distinct classes of Borrelia burgdorferi. J. Clin. Microbiol. 29:524-532.

34. Saitou, N., and M. Nei. 1987. The neighbor-joining method: a new method for reconstructing phylogenetic trees. Mol. Biol. Evol. 4:406-425.

35. Schwan, T. G., M. E. Schrumpf, R. H. Karstens, J. R. Clover, J. Wong, M. Daugherty, M. Struthers, and P. A. Rosa. 1993. Distribution and molecular analysis of Lyme disease spirochetes, Borrelia burgdorferi, isolated from ticks throughout California. J. Clin. Microbiol. 31:3096-3108.

36. Schwartz, I. 1994. Personal communication.

37. Schwartz, I., G. P. Wormser, J. J. Schwartz, D. Cooper, P. Weissensee, A. Gazumyan, E. Zimmermann, N. S. Goldberg, S. Bittker, G. L. Campbell, and C. S. Pavia. 1992. Diagnosis of early Lyme disease by polymerase chain reaction amplification and culture of skin biopsies from erythema migrans lesions. J. Clin. Microbiol. 30:3082-3088.

38. Schwartz, J. J., A. Gazumyan, and I. Schwartz. 1992. rRNA gene organization in the Lyme disease spirochete, Borrelia burgdorferi. J. Bacteriol. 174:3757-3765.

39. Stalhammar-Carlemalm, M., E. Jenny, L. Gern, A. Aeschlimann, and J. Meyer. 1990. Plasmid analysis and restriction fragment length polymorphisms of chromosomal DNA allow a distinction between Borrelia burgdorferi strains. Zentralbl. Bakteriol. 274:2839.

40. Theisen, M., B. Frederiksen, A. M. Lebech, J. Vuust, and K. Hansen. 1993. Polymorphism in ospC gene of Borrelia burgdorferi and immunoreactivity of OspC protein: implications for taxonomy and for use of OspC protein as a diagnostic antigen. J. Clin. Microbiol. 31:2570-2576.

41. Van Dam, A. P., H. Kuiper, K. Vos, A. Widjojokusumo, B. M. de Jongh, L. Spanjaard, A. C. P. Ramselaar, M. D. Kramer, and J. Dankert. 1993. Different genospecies of Borrelia burgdorferi are associated with distinct clinical manifestations of Lyme borreliosis. Clin. Infect. Dis. 17:708-717.

42. Wayne, L. G., D. J. Brenner, R. R. Colwell, P. A. D. Grimont, O. Kandler, M. I. Krichevsky, L. H. Moore, W. E. C. Moore, R. G. E. Murray, E. Stackebrandt, M. P. Starr, and H. G. Trüper. 1987. Report of the Ad Hoc Committee on Reconciliation of Approaches to Bacterial Systematics. Int. J. Syst. Bacteriol. 37:463464.

43. Welsh, J., C. Pretzman, D. Postic, I. Saint Girons, G. Baranton, and M. McClelland. 1992. Genomic fingerprinting by arbitrarily primed polymerase chain reaction resolves Borrelia burgdorferi into three distinct phyletic groups. Int. J. Syst. Bacteriol. 42:370-377.

44. Wilske, B., V. Preac-Mursic, U. B. Göbel, B. Graf, S. Jauris, E. Soutschek, E. Schwab, and G. Zumstein. 1993. An OspA serotyping system for Borrelia burgdorferi based on reactivity with monoclonal antibodies and OspA sequence analysis. J. Clin. Microbiol. 31:340-350.

45. Zingg, B. C., J. F. Anderson, R. C. Johnson, and R. B. LeFebvre. 1993. Comparative analysis of genetic variability among Borrelia burgdorferi isolates from Europe and the United States by restriction enzyme analysis, gene restriction fragment length polymorphism, and pulsed-field gel electrophoresis. J. Clin. Microbiol. 31:3115-3122

46. Zingg, B. C., R. N. Brown, R. S. Lane, and R. B. LeFebvre. 1993. Genetic diversity among Borrelia burgdorferi isolates from wood rats and kangaroo rats in California. J. Clin. Microbiol. 31:31093114. 